\title{
Database and data analysis application for structural characterization of gangliosides and sulfated glycosphingolipids by negative ion mass spectrometry
}

\author{
Marko Rožman a,*, Dragana Fabris ${ }^{\mathrm{b}}$, Tomislav Mrla ${ }^{\mathrm{a}}$, Željka Vukelić ${ }^{\mathrm{b}}$ \\ a Department of Physical Chemistry, Ruđer Bošković Institute, Bijenička 54, 10000 Zagreb, Croatia \\ ${ }^{\mathrm{b}}$ Department for Chemistry and Biochemistry, School of Medicine, University of Zagreb, Šalata 3, 10000 Zagreb, Croatia
}

\section{A B S T R A C T}

Gangliosides and sulfated glycosphingolipids, as building and functional components of animal cell mem-branes, participate in cell-to-cell interactions and signaling, but also in changes of cell architecture due to different pathophysiological events. In order to enable higher throughput and to facilitate structural characterization of gangliosides/sulfo-glycosphingolipids (GSL) and their neutral GSL counterparts by negative ion mass spectrometry (MS) and tandem MS techniques, a database and data analysis applica-tion have been developed. In silico developed glycosphingolipid database considers a high diversity of ceramide compositions, several sialic acid types ( $N$-acetylneuraminic acid, $N$-glycolylneuraminic acid and 2-keto-3-deoxynononic acid) as well as possible additional substitutions/modifications of glycosphingolipids, such as O-acetylation, de-N-acetylation, fucosylation, glucuronosylation, sulfation, attachment of repeating terminal hexose- $N$-acetylhexosamine- (Hex-HexNAc-) $)_{1-6}$ extension, and possi-ble lactone forms. Data analysis application, named GSL-finder, enables correlation of negative ion MS and/or low-energy tandem MS spectra with the database structures. The GSLdatabase construction and the GSL-finder application searching rules are explained. Validation conducted on GD1a fraction as well as on complex mixtures of native gangliosides isolated from different mammalian brain tissues (human fetal and adult brain, and calf brain tissue) demonstrated agreement with previous studies. Plain, fast, and automated routine for structural characterization of gangliosides/sulfated glycosphingolipids and their neutral GSL counterparts described here could facilitate and improve mass spectrometric analysis of complex glycosphingolipid mixtures originating from variety of normal and pathological biomaterial, where it is known that distinctive changes in glycosphingolipid composition occur.

\section{Introduction}

Acidic glycosphingolipid (GSLs) including gangliosides (GGs,

sialic acid-containing GSLs) and sulfated GSLs-are important building blocks of animal cell membranes. ${ }^{1}$ They participate in cell-to-cell and/or cell-substrate recognition/communication ${ }^{2-4}$ as well as in cell signaling. ${ }^{5}$ The highest concentration and structural heterogeneity of GGs have been found in mammalian brain tissues, and moreover their composition shows the brain region and the developmental stage specificity as well as specifically changes during aging. ${ }^{6,7}$ While simple sulfated GSLs (sulfatides) are also abundant in brain, more complex sulfoglucuronosyl-GSLs were found to be primarily localized in peripheral nerves. ${ }^{8-10}$ Disruption of GSL expression in brain causes abnormalities in cell architecture and leads to severe neurological disorders. ${ }^{1,6,11}$ Oncogenic transformations and some other pathological processes in cells/tissues are accompanied by changes in GSL metabolism and consequently, their impaired composition/expression at the cell surface directly affects cellular phenotype. ${ }^{12-17}$

Due to high structural diversity of both oligosaccharide and ceramide portion, GGs and sulfated GSLs are complex groups of glycolipids. Based on difference in structure of carbohydrate portion, more than 180 ganglioside species have been identified in vertebrates so far. Taking into consideration the heterogeneity in the ceramide part, the number of species increases manifold. ${ }^{1}$ GSL structural identity is strictly related to their functional properties as cell ligands and biomarkers. ${ }^{2,18}$ Elucidation of GSLs structureto-function relationships requires highly sensitive methods capable of detailed structural characterization. As GSLs are members of both glycome and lipidome, various analytical approaches for 
their analysis have been established among which mass spectrometry (MS) methods became unavoidable. During last three decades MS strategies for GSL characterization are constantly being developed and improved. ${ }^{16,17,19-24}$ Although MS and tandem MS approaches to generate spectral data have been successful, data analysis and interpretation still remains demanding and time consuming. Employment of MS for comparative compositional and structural characterization of complex GSL mixtures isolated from tissues and other biological material ${ }^{11,15,17,24-29}$ demands interpretation and comparison of large amount of data, in order to investigate their involvement/role and biomarker potential in physiological/biological processes in health and diseases. Therefore, researchers in glycolipidomics and biomedicine fields seek for assistance of applicable software tools.

Currently, a considerable number of databases and software tools for mass spectrometric data analysis and structural identification of various glycoconjugate and lipid classes are available. ${ }^{30-34}$ However, coverage of GSLs is mostly not comprehensive enough, so requirement for more complete GSL characterization tools has been recognized. LIPID MAPS ${ }^{33}$ and SysBio Ware glycomics software platform, ${ }^{34}$ as very useful tools, cover wide range of different GSL structures, but still have some limitations that may be restrictive for detailed characterization of complex GG and/or sulfo-GSL mixtures. For example, both databases do not include species that are $\mathrm{O}$-acetylated, de-N-acetylated, glucuronosylated nor various possible lactone forms. Glycosphingolipids containing such structural modifications are nowadays in research focus as they are often observed in pathologically changed versus healthy tissues. For example, many different tumor types contain O-acetylated and deN-acetylated GG structures. ${ }^{35,36}$ Also, LIPID MAPS do not offer possibility to analyze more than one tandem MS spectrum at the time.

To facilitate efforts toward new GSL characterization tools, in the present paper we demonstrate a computational GSL ion database for negative ion MS and MSMS ion spectra search. The database includes GGs and sulfo-GSLs as well as their neutral GSL counterparts. For comparing experimental MS data with those from the established database an application (GSL-finder) has been developed. Finally, we test and evaluate the database and GSL-finder on a commercially available GG fraction as well as on a complex native GG mixtures isolated from human (fetal and adult) and calf brain tissues.

\section{Materials and methods}

\subsection{Ganglioside samples}

Purified GD1a ganglioside fraction (disialoganglioside-GD1a, from bovine brain, minimum 95\% TLC) was purchased from Sigma-Aldrich (St Louis, USA). The native GG mixture analyzed in this study was isolated from fetal human brain (gestational age: 13 weeks). The GG mixture was extracted from brain tissue according to the method of Svennerholm and Fredman ${ }^{37}$ and modified by Vukelić et al. ${ }^{11}$ Lipids were extracted and re-extracted from the homogenized brain tissue using a chloroform/methanol/water mixture (1:2:0.75, by volume). To separate GGs from other lipids, the lipid extract was subjected to a phase partition and upper phases containing polar GSLs were collected. The crude GG extract was purified by precipitation and gel filtration on a Sephadex G-25 (Sigma-Aldrich, St Louis, USA) column. To preserve possible physiologically relevant alkali-labile species, no alkali hydrolysis step was performed during purification. The pure extract was evaporated and stored at $-20^{\circ} \mathrm{C}$. Permission for experiments with human brain tissue for scientific purposes was obtained from the Ethics Commission of the Zagreb School of Medicine, under the Project No. 108-1081870-2415.

\subsection{Mass spectrometry}

Analysis of GG samples was performed on a Bruker amaZon ETD ion trap system (Bruker Daltonik GmbH, Bremen, Germany) equipped with Apollo electrospray ionization source. Samples were dissolved in methanol to obtain $1.6 \mu \mathrm{M}$ concentration of GG-bound sialic acids and introduced into the electrospray ionization source by direct infusion at a flow rate of $65 \mu \mathrm{L} / \mathrm{h}$. The capillary voltage was set at $4500 \mathrm{~V}$ while high voltage end plate offset was $-500 \mathrm{~V}$. The temperature and flow rate of the drying gas were set at $210^{\circ} \mathrm{C}$ and $5 \mathrm{~L} / \mathrm{min}$, respectively. The electrospray ionization source parameters were optimized to allow an efficient ionization and to reduce the in-source fragmentation of molecular ions. Purified GD1a ganglioside fraction was used to test in-source fragmentation. During MS acquisition no desialylation artifacts such as GM1 or GA1 were observed. Helium was used as the collision gas. The isolation width of the precursor ion was set at $0.5-1 \mathrm{Da}$. The CID excitation time was $40 \mathrm{~ms}$ and the amplitude was in the $0.4-1 \mathrm{~V}$ range. All spectra were acquired in the negative ion mode using a scan range from $\mathrm{m} / \mathrm{z} 280$ to 3000 . Data Analysis software 4.0 (Bruker Daltonik GmbH, Bremen, Germany) was used for analysis (charge deconvolution and data reduction) and extraction of the MS and MSMS data.

\subsection{Algorithm and applications}

The algorithm for in silico generation of GSL database was written in Mathematica 8.0 (Wolfram Research Inc.). Several count and condition controlled loops were combined in order to iteratively construct GSL structures from their building blocks (ceramide, sialic acid, hexose, $N$-acetylhexosamine, etc.). A set of rules was applied to control compliance with the biosynthetically determined rules. Atomic masses of the most abundant isotopes were used to calculate the theoretical (monoisotopic) masses of GSL ions, using five decimal characters accuracy.

The GSL-finder MS is created as standalone Windows-based application for comparing MS data from imported reference list with the database according to selected search criteria.

The GSL-finder MSMS is application written in Mathematica 8.0 for correlating obtained tandem MS data with GSL database according to search criteria. The application requires Mathematica 8.0 or higher. Applications are available from the http://tinyurl.com/cd56ev6 (full link is provided in supporting data file). The installation manual containing instructions for users is provided together with the GSL-finder applications on the same webpage.

\section{Results and discussion}

\subsection{Building a database}

GLS database for MS ion search should provide the theoretical $\mathrm{m} / \mathrm{z}$ of a candidate structure/molecular formula for comparison to the actual measured $m / z$ of an ion within the given mass tolerance. Accordingly, our database was constructed to provide theoretical mass of a searched molecular ion $\left([\mathrm{M}-\mathrm{H}]^{-}\right)$followed by the description of its structure. For in silico generation of GSL structures, their basic building blocks (a particular ceramide, oligosaccharide chain and sialic acid/sulfate group) were used. Ceramide part of a molecule was constructed as a combination of 13 sphingoid base variations (including di- and trihydroxylated sphingoid bases) and 27 fatty acyl residues, giving a total of 351 ceramides. Hexose (isobaric sugars: galactose and glucose; Hex) and $\mathrm{N}$-acetylhexosamine (HexNAc) were main residues used for generating the neutral oligosaccharide chain. For GG sialylation status, 
$\mathrm{N}$-acetylneuraminic acid (NeuAc), $\mathrm{N}$-glycolylneuraminic acid (NeuGc) and 2-keto-3-deoxynononic acid (KDN) were considered. In addition to the common GSL building blocks, possible modifications by fucosylation (Fuc), O-acetylation, de-N-acetylation, sulfation, attachment of a glucuronic acid (GlcA) residue, repeating terminal hexose- $\mathrm{N}$-acetylhexosamine- (Hex-HexNAc- $)_{1-6}$ extension attachment, and formation of lactone were considered. Database components were created by addition of the building blocks and subsequent filtering, which checked whether the resulting GSL is in accordance with the biosynthetic rules. HexNAc units were restricted to structures containing more than one Hex unit considering the neutral oligosaccharide chain in structures of ganglio-, neolacto-, and lacto-series, and more than two Hex units for globo- and isoglobo-series. NeuAc unit was restricted to structures containing one and more Hex residues in the neutral oligosaccharide chain. Other sialic acid (NeuGc, KDN) residues were restricted to structures containing between one and four Hex units. NeuGc, KDN and NeuAc were allowed to be combined in the same structure. O-Ac-, di-O-Ac-, and de- $\mathrm{N}$-Ac-modifications were restricted to structures containing at least one sialic acid residue. $\mathrm{HSO}_{3}$-modification was restricted to neutral oligosaccharide chains, and to chains containing glucuronic acid (GlcA) residue. Fuc, Hex, HexNAc, and (Hex-HexNAc) 1-6 $_{6}$ units were considered as possible additional modifications when number of Hex units was greater than two. Lactone formation was restricted to structures containing at least two sialic acids.

The database also includes neutral GSLs and therefore starts with the $m / z 668$, which corresponds to HexCer with the shortest ceramide (d18:1/14:1). The highest included $m / z$ is $\sim 5000$ in order to cover theoretically possible complex GSL species with multiply repeating structural motifs, which is important for analysis of GSLs originating from tumor transformed tissues characterized by polysialylation and aberrant glycosylation. ${ }^{12,38}$ Modifications used to cover diversity of GSL structures which could possibly occur in normal and pathological tissues of different organisms, has resulted in a large number of database constituents $(\sim 148000$ structures). Main ganglio-series gangliosides and corresponding asialo-species included in the database are: GM1, GD1, GT1, GQ1, GP1, GH1, GM2, GD2, GT2, GQ2, GM3, GD3, GT3, GQ3, GM4, Gg4 or GA1, Gg3 or GA2, LacCer, and HexCer. Other included GSLs belong to lacto-, neolacto-, globo-, and isoglobo-series (nLc, Lc, $\mathrm{Gb}$ and iGb, respectively). The complete list of all oligosaccharide residues with different modifications and their sialylation/sulfation status can be found in supporting data file.

Usually in tandem MS ion search, once candidate sequences are determined from MS ion search, tandem mass spectrum can be compared with the expected fragmentation pattern of each candidate. The expected fragmentation pattern can be in a form of a database (of previously sequenced candidates) or can be created during the matching process. However, we identified several issues which affect generation of GSL fragmentation patterns and increase the search space. The first is the biosynthetically determined occurrence of GG structural isomers that differ according to the arrangement of sialic acid residues attached along the neutral oligosaccharide chain (e.g., Gal-GalNAc-Gal-Glc-Cer). Sialic acid residues are mostly linked to the inner or/and terminal Gal residue (as monosialo-, disialo- or trisialo residue). Therefore, with increasing number of sialic acid residues in more complex gangliosides, the number of combinations (i.e., isomers) is also increased making the structural identification more complicated. The second issue is additional complexity enhancement by adding modifications, especially if the sialic acid residue is modified, as in the case of O-acetylation. For example, an O-acetylated GQ1 (O-Ac-GQ1; four sialic acid residues among which one is O-acetylated) has 20 possible isoforms if structural isomerism of O-acetylated sialic acid is ignored (position of $O$-Ac within sialic acid). The third issue is the variety of product ion types. The negative ion mode fragmentation of GGs usually involves cleavage of the glycosidic bond. Product ions can be formed from the oligosaccharide end retaining the charge on the carbohydrate portion (designated as A, B, and C ions, according to the systematic nomenclature of glycoconjugate product ions ${ }^{39}$ ), or they can be formed from the lipid side containing ceramide residue alone or together with sugar units (designated as $\mathrm{X}, \mathrm{Y}$, and $\mathrm{Z}$ ions). The cleavage of the glycosidic bond at the reducing end of the molecule will produce $B$ or $Y$ ions, while cleavage at non-reducing end will produce $\mathrm{C}$ or $\mathrm{Z}$ ions, respectively. Therefore, each isoform of an $O$-Ac-GQ1 has between five and nine fragmentation patterns (depending on $O$-Ac and SA loss) giving all together 140 patterns for 20 isoforms. However, most of the patterns are not distinctive and $O$-Ac-GQ1 example has only two patterns with unique isoform identification.

In general, negative ion low-energy CID of GG molecular ions readily display abundant loss of sialic acid moieties and cleavage of the glycosidic bonds at the reducing end of the molecule. The released monosialo-fragment is represented by $B_{1}, B_{1 \alpha}$, and/or $B_{1 \beta}$ product ions, while cleavage of the glycosidic bond with retention of the glycosidic oxygen atom yields $Y_{n}$ ions. So, the major product ions ( $\mathrm{Y}$ - and most of Z-ions) of a glycosphingolipid fragmentation pattern are structurally identical to the corresponding simpler glycosphingolipid species. Therefore, the tandem MS ion search is simplified in such a manner that MS ion database is used for matching tandem MS spectra. As an illustration, O-Ac-GD3 (d18:1/18:0) was fragmented by a low-energy CID (Fig. 1) and major product ions observed are designated $Y_{3},\left[Y_{3}-A c\right], Y_{2}, B_{1}, B_{2}$, and $\mathrm{B}_{2}$-Ac (Fig. 1a). The same spectrum designated according to the tandem MS ion search is represented in Figure $1 \mathrm{~b}$. The product ion $[\mathrm{M}-\mathrm{H}-\mathrm{Ac}]^{-}$corresponds to GD3 structure while the ions $\mathrm{Y}_{3}$, $\left[\mathrm{Y}_{3}-\mathrm{Ac}\right]$, and $\mathrm{Y}_{2}$ correspond to $\mathrm{O}-\mathrm{Ac}-\mathrm{GM} 3, \mathrm{GM} 3$, and LacCer, respectively. Assignment of the sialic acid fragments was done by using separately created database with sialic acid residues and their modifications (O-acetylation and de-N-acetylation).

(a)
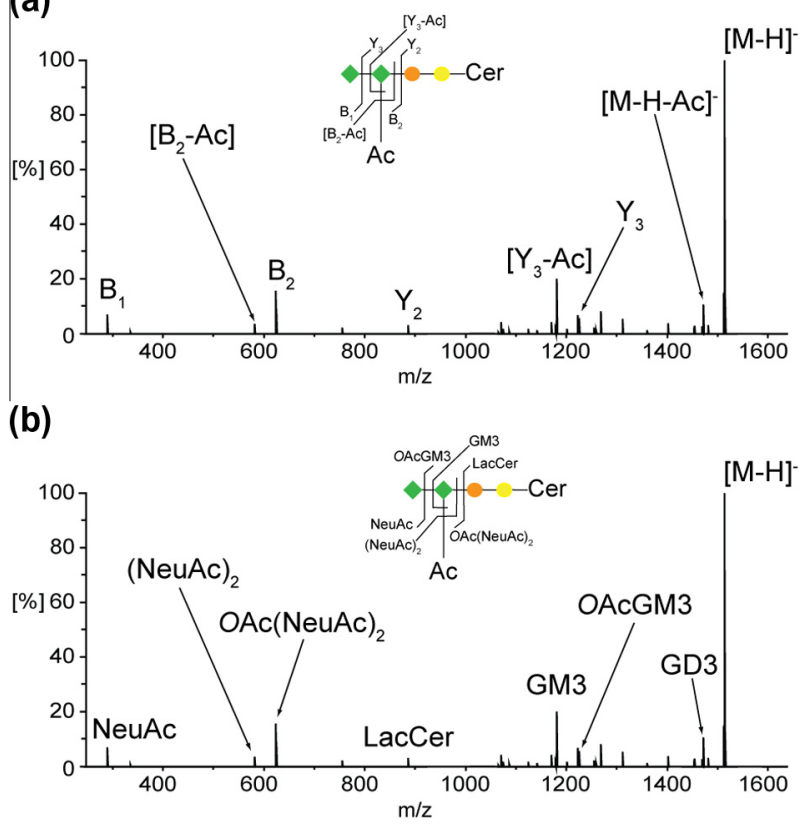

Figure 1. Low-energy CID spectrum of $O$-Ac-GD3 (d18:1/18:0). Product ions labeled according to: (a) nomenclature proposed by Domon and Costello; ${ }^{39}$ (b) GSL-finder MSMS ion search (the spectrum was manually annotated on a basis of GSL-finder MSMS output). 


\subsection{Database searching}

GSL-finder applications (MS and MSMS) are designed to compare the experimental data with the database. To create a list of ions $m / z$ values intended to be searched against the GSL-finder database, experimentally obtained MS and/or tandem MS data should be preformatted in such way that all multiply charged ions are deconvoluted to singly charged negative ions. One can consider to eliminate noise from the spectrum as well as to reduce the number of ions. At the moment program does not take into account ion intensities and the search list should contain only the ions $m / z$ values. The requirement for the candidate MS ion search list is that each ion should be written in a separate line. For the MSMS ion search list, a precursor ion mass should be followed by the masses of its product ions in the same line. Next precursor ion together with the masses of its product ions should follow in a new line. Prior to MS or MSMS database search, a desired mass tolerance $(\Delta m)$ should be defined. A user can also exclude some or all structural modifications: fucosylation (Fuc), O-acetylation, de-N-acetylation, sulfation, attachment of hexose- $N$-acetylhexosamine (Hex-HexNAc) or glucuronic acid (GlcA) residues, and presence of lactone. At the completion of the MS ion search the GSL-finder MS provides a list of GSLs that match the measured mass. Each output on the list contains the following information: measured mass, theoretical mass, difference between the experimental and calculated masses, name of the theoretical GSL. The matched measured mass is a prerequisite for MSMS ion search where the results are ranked on a basis of the highest score. Tandem MS scoring is based on a number of the diagnostic ions from the database that match ions observed in the spectrum. Each ranked GSL also contains information about experimental and theoretical mass, difference between the experimental and calculated masses, name of the theoretical GSL, number and type of matched sialic acid residues (including modified sialic acid moieties), structure of Y- and Z-ions according to the basic building blocks.

\subsection{Limitations of the database and database searching}

Developed database and GSL-finder applications hold some constrains which potential user has to have in mind. (I) As already mentioned above, spectra processing is not performed by GSL-finder applications. Spectra need to be preprocessed and all multiply charged ions deconvoluted to the singly charged deprotonated ions. (II) Database and GSL-finder applications are tuned for negative ion mode. According to available literature data and our own experimental experience gangliosides and sulfo-glycosphingolipids ionize more readily in the negative versus positive ion mode. ${ }^{40,41}$ (III) At present, the GSL-finder MSMS application do not assign cross-ring cleavage product ions since the MS ion database is used for matching tandem MS spectra, vide supra. (IV) Monosaccharide isomers, Glc versus Gal and GlcNAc versus GalNAc, cannot be distinguished, nor can consequently be distinguished two or more analogous oligosaccharide residues differing by these monosaccharide units (e.g., Gg3 vs Lc3). (V) Isomeric ceramide structures cannot be distinguished. The GSL-finder MS and MSMS search results give the most probable (common) naturally occurring ceramide structures/isomers, corresponding to the selected $\mathrm{m} / \mathrm{z}$ value, in the form sphingoid base/fatty acid. The provided sphingoid base and fatty acid residue structures, although the most probable, are tentative, and could be confirmed only by further MS sequencing of the ceramide ion. (VI) Due to the high diversity of GSL structures present in the database, GSL-finder MSMS search results may contain considerable rate of false positive suggestions. False positive suggestions were defined as incorrectly identified GSL species with a higher score than a true positive. The rate of the false positive suggestions for GSL mixtures used for testing and validation of the database was around $19.6 \%$. However, this can be reduced by defining possible structural modifications, types of sialic acids and ceramides prior to search against database. An 'educated guess' about the sample type is desirable, for example, gangliosides from human tissue samples lack NeuGc sialic acids and contain mainly ceramides with even number of carbon atoms. Moreover, one should eliminate or at least very carefully evaluate a search result suggesting an acetylated ganglioside without signals that correspond to the acetylated sialic acid moiety. Having all that in mind, a rate of the false positive suggestions for tested GSL mixtures was reduced to $6 \%$.

\subsection{Testing and validation of the database}

In order to test and validate the GSL-finder application and the database, we have applied it to the analysis of several GSL mixtures from different biomaterial: the purified GD1a ganglioside fraction from bovine brain, complex ganglioside mixtures from both fetal and adult human brain, as well as complex ganglioside mixture from calf brain. Additionally, we have recently successfully applied the GSL-finder to the analysis of brain gangliosides from mice with altered ganglioside biosynthesis. ${ }^{42}$

\subsubsection{GD1a ganglioside fraction}

The most abundant signals in MS spectra of the GD1a ganglioside fraction from bovine brain were doubly charged negative ions at $m / z 917.5$ and 931.5 , respectively. The ions were selected and fragmented by low-energy CID (Fig. 2). A range of product ions were produced representing cleavages of glycosidic bonds. In order to perform structural identification (and validation of the GSL-finder database), all multiply charged ions were deconvoluted to singly charged ions and the ion list was created following the requirements for MSMS ion search list.

MSMS database search of the product ions obtained from the double charged molecular ion at $m / z 917.5$ returned two species with the highest score: GD1 (d18:1/18:0) and GD1 (t18:1/17:1); complete search results can be found in supporting data file. Both species have the same number of the diagnostic ions matching the

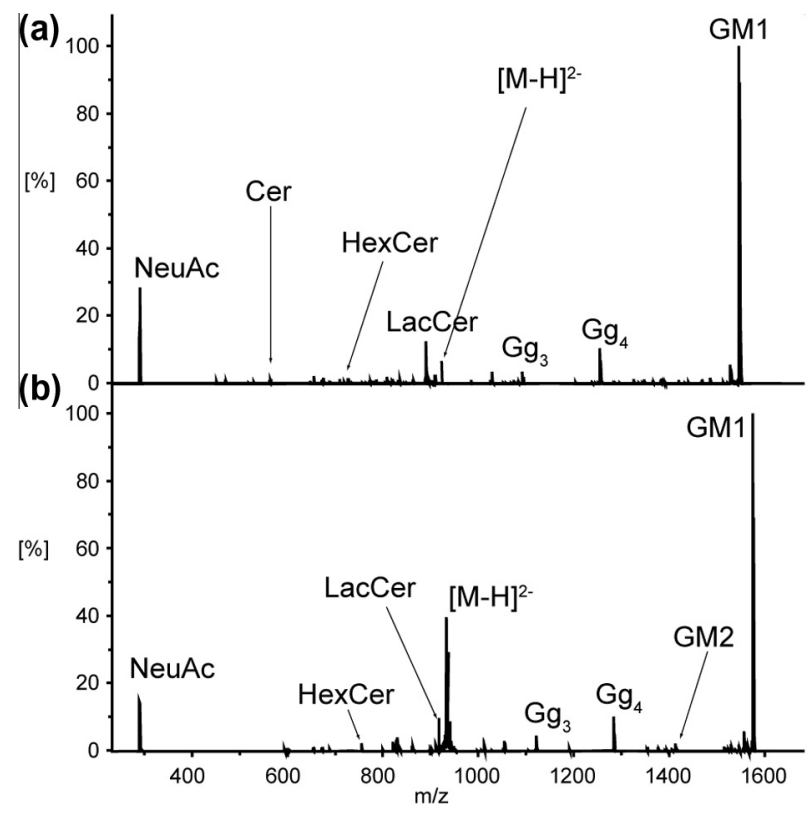

Figure 2. Product ion spectra of the double charged ions at $m / z 917.5$ (a) and 931.5 (b) corresponding to GD1a (d18:1/18:0) and GD1a (d18:1/20:0) or (d20:1/18:0) respectively. The spectra were manually annotated on a basis of GSL-finder MSMS output. 
Table 1

Ganglioside composition of the fetal human brain in 13th g.w., as obtained by matching experimental MS data with the GSL-finder MS and MSMS database search

\begin{tabular}{|c|c|c|}
\hline Experimental $(m / z)$ & Mass accuracy (ppm) & Proposed structure $^{a}$ \\
\hline 857.55 & 37 & Phosphatidylinositol (36:4) \\
\hline 883.55 & 23 & Phosphatidylinositol $(38: 5)^{\mathrm{b}}$ \\
\hline 885.58 & 33 & Phosphatidylinositol $(38: 4)^{\mathrm{b}}$ \\
\hline 1151.60 & 92 & GM3 $(\mathrm{d} 18: 1 / 16: 0)$ or $(\mathrm{d} 20: 1 / 14: 0)$ or $(\mathrm{d} 18: 0 / 16: 1)$ or $(\mathrm{d} 20: 0 / 14: 1) \ldots$ \\
\hline 1179.70 & 32 & GM3 $(\mathrm{d} 18: 1 / 18: 0)$ or $(\mathrm{d} 20: 1 / 16: 0)$ or $(\mathrm{d} 22: 1 / 14: 0)$ or $(\mathrm{d} 18: 0 / 18: 1) \ldots$ \\
\hline 1253.80 & 21 & GA1 $(\mathrm{d} 18: 1 / 18: 0)$ or $(\mathrm{d} 20: 1 / 16: 0)$ or $(\mathrm{d} 22: 1 / 14: 0)$ or $(\mathrm{d} 18: 0 / 18: 1) \ldots$ \\
\hline 1261.80 & 12 & GM3 $(\mathrm{d} 18: 1 / 24: 1)$ or $(\mathrm{d} 20: 1 / 22: 1)$ or $(\mathrm{d} 22: 1 / 20: 1)$ or $(\mathrm{d} 24: 1 / 18: 1) \ldots$ \\
\hline 1382.80 & 12 & GM2 $(\mathrm{d} 18: 1 / 18: 0)$ or $(\mathrm{d} 20: 1 / 16: 0)$ or $(\mathrm{d} 22: 1 / 14: 0)$ or $(\mathrm{d} 18: 0 / 18: 1) \ldots$ \\
\hline 1442.60 & 140 & GD3 $(\mathrm{d} 18: 1 / 16: 0)$ or $(\mathrm{d} 20: 1 / 14: 0)$ or $(\mathrm{d} 18: 0 / 16: 1)$ or $(\mathrm{d} 20: 0 / 14: 1) \ldots$ \\
\hline 1470.79 & 29 & GD3 $(\mathrm{d} 18: 1 / 18: 0)$ or $(\mathrm{d} 20: 1 / 16: 0)$ or $(\mathrm{d} 22: 1 / 14: 0)$ or $(\mathrm{d} 18: 0 / 18: 1) \ldots$ \\
\hline 1516.69 & 98 & GM1 $(\mathrm{d} 18: 1 / 16: 0)$ or $(\mathrm{d} 20: 1 / 14: 0)$ or $(\mathrm{d} 18: 0 / 16: 1)$ or $(\mathrm{d} 20: 0 / 14: 1) \ldots$ \\
\hline 1542.90 & 30 & GM1 $(\mathrm{d} 18: 1 / 18: 1)$ or $(\mathrm{d} 20: 1 / 16: 1)$ or $(\mathrm{d} 22: 1 / 14: 1)$ or $(\mathrm{d} 16: 1 / 20: 1) \ldots$ \\
\hline 1544.80 & 45 & GM1 $(\mathrm{d} 18: 1 / 18: 0)$ or $(\mathrm{d} 20: 1 / 16: 0)$ or $(\mathrm{d} 22: 1 / 14: 0)$ or $(\mathrm{d} 18: 0 / 18: 1) \ldots$ \\
\hline 1572.80 & 64 & GM1 (d18:1/20:0) or $(\mathrm{d} 20: 1 / 18: 0)$ or $(\mathrm{d} 22: 1 / 16: 0)$ or $(\mathrm{d} 24: 1 / 14: 0) \ldots$ \\
\hline 1626.77 & 109 & GM1 $(\mathrm{d} 18: 1 / 24: 1)$ or $(\mathrm{d} 20: 1 / 22: 1)$ or $(\mathrm{d} 22: 1 / 20: 1)$ or $(\mathrm{d} 24: 1 / 18: 1) \ldots$ \\
\hline 1645.69 & 116 & GD2 $(\mathrm{d} 18: 1 / 16: 0)$ or $(\mathrm{d} 20: 1 / 14: 0)$ or $(\mathrm{d} 18: 0 / 16: 1)$ or $(\mathrm{d} 20: 0 / 14: 1) \ldots$ \\
\hline 1673.77 & 85 & GD2 $(\mathrm{d} 18: 1 / 18: 0)$ or $(\mathrm{d} 20: 1 / 16: 0)$ or $(\mathrm{d} 22: 1 / 14: 0)$ or $(\mathrm{d} 18: 0 / 18: 1) \ldots$ \\
\hline 1701.80 & 84 & GD2 $(\mathrm{d} 18: 1 / 20: 0)$ or $(\mathrm{d} 20: 1 / 18: 0)$ or $(\mathrm{d} 22: 1 / 16: 0)$ or $(\mathrm{d} 24: 1 / 14: 0) \ldots$ \\
\hline 1807.78 & 85 & GD1 $(\mathrm{d} 18: 1 / 16: 0)$ or $(\mathrm{d} 20: 1 / 14: 0)$ or $(\mathrm{d} 18: 0 / 16: 1)$ or $(\mathrm{d} 20: 0 / 14: 1) \ldots$ \\
\hline 1833.86 & 49 & GD1 $(\mathrm{d} 18: 1 / 18: 1)$ or $(\mathrm{d} 20: 1 / 16: 1)$ or $(\mathrm{d} 22: 1 / 14: 1)$ or $(\mathrm{d} 16: 1 / 20: 1) \ldots$ \\
\hline 1835.82 & 79 & GD1 $(\mathrm{d} 18: 1 / 18: 0)$ or $(\mathrm{d} 20: 1 / 16: 0)$ or $(\mathrm{d} 22: 1 / 14: 0)$ or $(\mathrm{d} 18: 0 / 18: 1) \ldots$ \\
\hline 1849.79 & 83 & OAc GD1 $(\mathrm{d} 18: 1 / 16: 0)$ or $(\mathrm{d} 20: 1 / 14: 0)$ or $(\mathrm{d} 18: 0 / 16: 1)$ or $(\mathrm{d} 20: 0 / 14: 1) \ldots$ \\
\hline $1857.71^{\mathrm{Na}}$ & 127 & GD1 $(\mathrm{d} 18: 1 / 18: 0)$ or $(\mathrm{d} 20: 1 / 16: 0) \ldots+\mathrm{Na}$ \\
\hline 1863.83 & 89 & GD1 $(\mathrm{d} 18: 1 / 20: 0)$ or $(\mathrm{d} 20: 1 / 18: 0)$ or $(\mathrm{d} 22: 1 / 16: 0)$ or $(\mathrm{d} 24: 1 / 14: 0) \ldots$ \\
\hline 1891.90 & 67 & GD1 $(\mathrm{d} 18: 1 / 22: 0)$ or $(\mathrm{d} 20: 1 / 20: 0)$ or $(\mathrm{d} 22: 1 / 18: 0)$ or $(\mathrm{d} 24: 1 / 16: 0) \ldots$ \\
\hline 1893.86 & 97 & GD1 $(\mathrm{d} 18: 0 / 22: 0)$ or $(\mathrm{d} 20: 0 / 20: 0)$ or $(\mathrm{d} 22: 0 / 18: 0)$ or $(\mathrm{d} 24: 0 / 16: 0) \ldots$ \\
\hline 1917.98 & 33 & GD1 $(\mathrm{d} 18: 1 / 24: 1)$ or $(\mathrm{d} 20: 1 / 22: 1)$ or $(\mathrm{d} 22: 1 / 20: 1)$ or $(\mathrm{d} 24: 1 / 18: 1) \ldots$ \\
\hline 1919.96 & 51 & GD1 $(\mathrm{d} 18: 1 / 24: 0)$ or $(\mathrm{d} 20: 1 / 22: 0)$ or $(\mathrm{d} 22: 1 / 20: 0)$ or $(\mathrm{d} 24: 1 / 18: 0) \ldots$ \\
\hline 2098.89 & 66 & GT1 $(\mathrm{d} 18: 1 / 16: 0)$ or $(\mathrm{d} 20: 1 / 14: 0)$ or $(\mathrm{d} 18: 0 / 16: 1)$ or $(\mathrm{d} 20: 0 / 14: 1) \ldots$ \\
\hline 2124.89 & 73 & GT1 $(\mathrm{d} 18: 1 / 18: 1)$ or $(\mathrm{d} 20: 1 / 16: 1)$ or $(\mathrm{d} 22: 1 / 14: 1)$ or $(\mathrm{d} 16: 1 / 20: 1) \ldots$ \\
\hline 2126.88 & 85 & GT1 $(\mathrm{d} 18: 1 / 18: 0)$ or $(\mathrm{d} 20: 1 / 16: 0)$ or $(\mathrm{d} 22: 1 / 14: 0)$ or $(\mathrm{d} 18: 0 / 18: 1) \ldots$ \\
\hline $2148.92^{\mathrm{Na}}$ & 57 & GT1 $(\mathrm{d} 18: 1 / 18: 0)$ or $(\mathrm{d} 20: 1 / 16: 0) \ldots+\mathrm{Na}$ \\
\hline 2208.89 & 112 & GT1 $(\mathrm{d} 18: 1 / 24: 1)$ or $(\mathrm{d} 20: 1 / 22: 1)$ or $(\mathrm{d} 22: 1 / 20: 1)$ or $(\mathrm{d} 24: 1 / 18: 1) \ldots$ \\
\hline 2200.91 & 85 & (Hex-HexNAc) GD1 (d18:1/18:0) or $(\mathrm{d} 20: 1 / 16: 0)$ or $(\mathrm{d} 22: 1 / 14: 0) \ldots$ \\
\hline
\end{tabular}

a Only most likely ceramide residues are shown. Other possible ceramide combinations can be found in Supporting information Table 1-SI.

b Structures assigned manually; phospholipids are not included in the database.

ions observed in the fragmentation spectrum, because their ceramides have similar molecular masses ( $0.0364 \mu$ mass difference). However, knowing that GD1 (d18:1/18:0) predominates in mammalian (i.e., bovine) brain tissue, ${ }^{43,44}$ we can assume that fragmented ion was GD1 (d18:1/18:0). Finally, considering the absence of the ion at $m / z 581$ (Fig. 2a), which corresponds to [NeuAc-NeuAc-H $]^{-}$, and having highly abundant ion at $m / z 290$ ([Neu$\mathrm{Ac}-\mathrm{H}]^{-}$), we can conclude that the analyzed isomer was GD1a.

MSMS ion search of the product ions obtained from the double charged molecular ion at $m / z 931.5$ also identified two species with the highest score: GD1 (d18:1/20:0) or (d20:1/18:0) and GD1 (t18:1/19:1); complete search results can be found in supporting data file. GSLs with even numbered sphingoid bases and fatty acid residues are much more abundant in mammalian brain tissue than odd numbered, which are only present in traces in bovine brain tissue. ${ }^{41,45}$ While sphingosine (d18:1) predominates, the sphingoid base d20:1 is also quite abundant in GSLs of mammalian nervous system. ${ }^{44}$ Therefore, we believe that fragmented ion was GD1 (d18:1/20:0) or (d20:1/18:0), and also belonging to a-series of gangliosides due to the absence of $m / z 581$ product ion, while showing highly abundant ion at $\mathrm{m} / \mathrm{z} 290$ corresponding to NeuAc residue (Fig. 2b).

\subsubsection{Native ganglioside mixtures from human and calf brain tissue}

To test the GSL-finder on 'real life' samples, a native ganglioside mixture isolated from fetal human brain (13th gestational week, g.w.), adult human brain (54 years), and calf brain tissue were analyzed.

\subsubsection{Fetal human brain gangliosides analysis}

The MS scan contained a total of 40 signals (Fig. 1-SI in Supplementary material). Due to the difficulty to isolate and fragment the low abundance ions, only signals above $2 \%$ relative intensity were subjected to tandem MS. All acquired tandem MS spectra were combined and searched against GSL-finder database. The list of candidate gangliosides produced by GSL-finder was additionally reevaluated in a way that:

- ceramides with even numbered sphingoid bases and fatty acids are preferred, vide supra;

- acetylated gangliosides without signals that correspond to acetylated sialic acid moiety, are ignored;

- gangliosides with greater number of Y-ions are preferred.

The final search results are shown in Table 1. Complete results of the analysis are summarized in Table 1-SI in Supporting information. Obtained structures from Table 1 were compared with previously reported (manually interpreted) ganglioside analysis of human fetal hippocampi (15 and 17 g.w.). ${ }^{25}$ The brain samples showed high resemblance in general GG pattern, sharing all common ganglioside species characteristically present in fetal human brain (GM3, GM2, GD3, GD2, GM1, GD1, GT1). Signals with highest intensity in all brain tissues samples correspond to GD1 (d18:1/ 18:0) and GT1 (d18:1/18:0). Differences related to the charge states and frequency of sodiated species are attributed to the different MS instruments used. Small alteration in GG species composition and differences in individual GG abundances (e.g., higher abundance of GD3 and higher diversity of GD1 and GT1 species 
Table 2

Ganglioside composition of the adult human brain (54 years), as obtained by matching experimental MS data with the GSL-finder MS

\begin{tabular}{|c|c|c|}
\hline Experimental $(\mathrm{m} / \mathrm{z})$ & Mass accuracy (ppm) & Proposed structure $^{\mathrm{a}}$ \\
\hline 788.60 & 63 & Phosphatidylserine $(36: 1)^{\mathrm{b}}$ \\
\hline 806.66 & 124 & Phosphatidylserine $(38: 6)^{\mathrm{b}}$ \\
\hline 816.60 & 245 & Phosphatidylserine $(38: 1)^{\mathrm{b}}$ \\
\hline 835.56 & 36 & Phosphatidylinositol $(34: 1)^{\mathrm{b}}$ \\
\hline 857.54 & 23 & Phosphatidylinositol $(36: 4)^{\mathrm{b}}$ \\
\hline 861.68 & 151 & Phosphatidylinositol $(36: 2)^{\mathrm{b}}$ \\
\hline 878.62 & 23 & $\mathrm{HSO}_{3}$-Hex-Cer $(\mathrm{t} 18: 1 / 22: 0)$ or $(\mathrm{d} 18: 1 / \mathrm{h} 22: 0)$ or $(\mathrm{t} 18: 0 / 22: 1) \ldots$ \\
\hline 883.55 & 23 & Phosphatidylinositol $(38: 5)^{\mathrm{b}}$ \\
\hline 885.58 & 33 & Phosphatidylinositol $(18: 0 / 20: 4)=(38: 4)^{\mathrm{b}}$ \\
\hline 888.64 & 18 & $\mathrm{HSO}_{3}-\mathrm{Hex}-\mathrm{Cer}(\mathrm{d} 18: 1 / 24: 1)$ or $(\mathrm{d} 20: 1 / 22: 1)$ or $(\mathrm{d} 22: 1 / 20: 1) \ldots$ \\
\hline 892.66 & 6 & $\mathrm{HSO}_{3}-\mathrm{Hex}-\mathrm{Cer}(\mathrm{d} 18: 0 / 24: 0)$ or $(\mathrm{d} 20: 0 / 22: 0)$ or $(\mathrm{d} 22: 0 / 20: 0) \ldots$ \\
\hline 902.66 & 63 & $\mathrm{HSO}_{3}$-Hex-Cer (d18:1/25:1) or(t18:1/24:2) or $(\mathrm{d} 18: 1 / \mathrm{h} 24: 2)$ \\
\hline 904.70 & 50 & $\mathrm{HSO}_{3}$-Hex-Cer $(\mathrm{d} 18: 1 / 25: 0)$ or $(\mathrm{d} 20: 1 / 23: 0) \ldots$ \\
\hline 906.68 & 31 & LacCer (t18:0/18:0) \\
\hline 1179.76 & 17 & GM3 $(\mathrm{d} 18: 1 / 18: 0)$ or $(\mathrm{d} 20: 1 / 16: 0)$ or $(\mathrm{d} 22: 1 / 14: 0)$ or $(\mathrm{d} 18: 0 / 18: 1) \ldots$ \\
\hline 1207.78 & 8 & GM3 $(\mathrm{d} 18: 1 / 20: 0)$ or $(\mathrm{d} 20: 1 / 18: 0)$ or $(\mathrm{d} 22: 1 / 16: 0)$ or $(\mathrm{d} 24: 1 / 14: 0) \ldots$ \\
\hline 1382.75 & 51 & GM2 $(\mathrm{d} 18: 1 / 18: 0)$ or $(\mathrm{d} 20: 1 / 16: 0)$ or $(\mathrm{d} 22: 1 / 14: 0)$ or $(\mathrm{d} 18: 0 / 18: 1) \ldots$ \\
\hline 1410.75 & 71 & GM2 (d18:1/20:0) or $(\mathrm{d} 20: 1 / 18: 0)$ or $(\mathrm{d} 22: 1 / 16: 0)$ or $(\mathrm{d} 24: 1 / 14: 0) \ldots$ \\
\hline 1470.86 & 20 & GD3 $(\mathrm{d} 18: 1 / 18: 0)$ or $(\mathrm{d} 20: 1 / 16: 0)$ or $(\mathrm{d} 22: 1 / 14: 0)$ or $(\mathrm{d} 18: 0 / 18: 1) \ldots$ \\
\hline 1498.81 & 31 & GD3 $(\mathrm{d} 18: 1 / 20: 0)$ or $(\mathrm{d} 20: 1 / 18: 0)$ or $(\mathrm{d} 22: 1 / 16: 0)$ or $(\mathrm{d} 24: 1 / 14: 0) \ldots$ \\
\hline 1516.74 & 66 & GM1 $(\mathrm{d} 18: 1 / 16: 0)$ or $(\mathrm{d} 20: 1 / 14: 0)$ or $(\mathrm{d} 18: 0 / 16: 1)$ or $(\mathrm{d} 20: 0 / 14: 1) \ldots$ \\
\hline 1542.92 & 45 & GM1 $(\mathrm{d} 18: 1 / 18: 1)$ or $(\mathrm{d} 20: 1 / 16: 1)$ or $(\mathrm{d} 22: 1 / 14: 1)$ or $(\mathrm{d} 16: 1 / 20: 1) \ldots$ \\
\hline 1544.76 & 71 & GM1 $(\mathrm{d} 18: 1 / 18: 0)$ or $(\mathrm{d} 20: 1 / 16: 0)$ or $(\mathrm{d} 22: 1 / 14: 0)$ or $(\mathrm{d} 18: 0 / 18: 1) \ldots$ \\
\hline 1572.78 & 76 & GM1 (d18:1/20:0) or $(\mathrm{d} 20: 1 / 18: 0)$ or $(\mathrm{d} 22: 1 / 16: 0)$ or $(\mathrm{d} 24: 1 / 14: 0) \ldots$ \\
\hline 1600.93 & 1 & GM1 $(\mathrm{d} 18: 1 / 22: 0)$ or $(\mathrm{d} 20: 1 / 20: 0)$ or $(\mathrm{d} 22: 1 / 18: 0)$ or $(\mathrm{d} 24: 1 / 16: 0) \ldots$ \\
\hline 1673.76 & 90 & GD2 $(\mathrm{d} 18: 1 / 18: 0)$ or $(\mathrm{d} 20: 1 / 16: 0)$ or $(\mathrm{d} 22: 1 / 14: 0)$ or $(\mathrm{d} 18: 0 / 18: 1) \ldots$ \\
\hline 1702.35 & 241 & GD2 $(\mathrm{d} 18: 1 / 20: 0)$ or $(\mathrm{d} 20: 1 / 18: 0)$ or $(\mathrm{d} 22: 1 / 16: 0)$ or $(\mathrm{d} 24: 1 / 14: 0) \ldots$ \\
\hline 1836.03 & 38 & GD1 $(\mathrm{d} 18: 1 / 18: 0)$ or $(\mathrm{d} 20: 1 / 16: 0)$ or $(\mathrm{d} 22: 1 / 14: 0)$ or $(\mathrm{d} 18: 0 / 18: 1) \ldots$ \\
\hline $1857.68^{\mathrm{Na}}$ & 145 & GD1 $(\mathrm{d} 18: 1 / 18: 0)$ or $(\mathrm{d} 20: 1 / 16: 0)$ or $(\mathrm{d} 22: 1 / 14: 0)$ or $(\mathrm{d} 18: 0 / 18: 1) \ldots+\mathrm{Na}$ \\
\hline 1863.71 & 156 & GD1 $(\mathrm{d} 18: 1 / 20: 0)$ or $(\mathrm{d} 20: 1 / 18: 0)$ or $(\mathrm{d} 22: 1 / 16: 0)$ or $(\mathrm{d} 24: 1 / 14: 0) \ldots$ \\
\hline 1878.36 & 205 & OAc GD1 $(\mathrm{d} 18: 1 / 18: 0)$ or $(\mathrm{d} 20: 1 / 16: 0)$ or $(\mathrm{d} 22: 1 / 14: 0)$ or $(\mathrm{d} 18: 0 / 18: 1) \ldots$ \\
\hline 1892.93 & 106 & GD1 $(\mathrm{d} 18: 1 / 22: 0)$ or $(\mathrm{d} 20: 1 / 20: 0)$ or $(\mathrm{d} 22: 1 / 18: 0)$ or $(\mathrm{d} 24: 1 / 16: 0) \ldots$ \\
\hline 1899.94 & 47 & GD1 $(\mathrm{d} 18: 1 / 24: 1)$ or $(\mathrm{d} 20: 1 / 22: 1)$ or $(\mathrm{d} 22: 1 / 20: 1)$ or $(\mathrm{d} 24: 1 / 18: 1) \ldots-\mathrm{H}_{2} \mathrm{O}$ \\
\hline 1906.08 & 37 & OAc GD1 $(\mathrm{d} 18: 1 / 20: 0)$ or $(\mathrm{d} 20: 1 / 18: 0)$ or $(\mathrm{d} 22: 1 / 16: 0)$ or $(\mathrm{d} 24: 1 / 14: 0) \ldots$ \\
\hline 1920.08 & 10 & GD1 $(\mathrm{d} 18: 1 / 24: 0)$ or $(\mathrm{d} 20: 1 / 22: 0)$ or $(\mathrm{d} 22: 1 / 20: 0)$ or $(\mathrm{d} 24: 1 / 18: 0) \ldots$ \\
\hline 1921.96 & 57 & GD1 $(\mathrm{d} 18: 0 / 24: 0)$ or $(\mathrm{d} 20: 0 / 22: 0)$ or $(\mathrm{d} 22: 0 / 20: 0)$ or $(\mathrm{d} 24: 0 / 18: 0) \ldots$ \\
\hline 2038.87 & 83 & $($ HexNAc) GD1 $(\mathrm{d} 18: 1 / 18: 0)$ or $(\mathrm{d} 20: 1 / 16: 0)$ or $(\mathrm{d} 22: 1 / 14: 0) \ldots$ \\
\hline 2067.11 & 15 & (HexNAc) GD1 (d18:1/20:0) or (d20:1/18:0) or $(\mathrm{d} 22: 1 / 16: 0) \ldots$ \\
\hline 2127.01 & 24 & GT1 $(\mathrm{d} 18: 1 / 18: 0)$ or $(\mathrm{d} 20: 1 / 16: 0)$ or $(\mathrm{d} 22: 1 / 14: 0)$ or $(\mathrm{d} 18: 0 / 18: 1) \ldots$ \\
\hline $2148.91^{\mathrm{Na}}$ & 60 & GT1 $(\mathrm{d} 18: 1 / 18: 0)$ or $(\mathrm{d} 20: 1 / 16: 0)$ or $(\mathrm{d} 22: 1 / 14: 0)$ or $(\mathrm{d} 18: 0 / 18: 1) \ldots+\mathrm{Na}$ \\
\hline 2155.07 & 9 & GT1 $(\mathrm{d} 18: 1 / 20: 0)$ or $(\mathrm{d} 20: 1 / 18: 0)$ or $(\mathrm{d} 22: 1 / 16: 0)$ or $(\mathrm{d} 24: 1 / 14: 0) \ldots$ \\
\hline $2176.89^{\mathrm{Na}}$ & 83 & GT1 $(\mathrm{d} 18: 1 / 20: 0)$ or $(\mathrm{d} 20: 1 / 18: 0)$ or $(\mathrm{d} 22: 1 / 16: 0)$ or $(\mathrm{d} 24: 1 / 14: 0) \ldots+\mathrm{Na}$ \\
\hline 2168.89 & 83 & OAc GT1 $(\mathrm{d} 18: 1 / 18: 0)$ or $(\mathrm{d} 20: 1 / 16: 0)$ or $(\mathrm{d} 22: 1 / 14: 0)$ or $(\mathrm{d} 18: 0 / 18: 1) \ldots$ \\
\hline 2183.01 & 50 & GT1 $(\mathrm{d} 18: 1 / 22: 0)$ or $(\mathrm{d} 20: 1 / 20: 0)$ or $(\mathrm{d} 22: 1 / 18: 0)$ or $(\mathrm{d} 24: 1 / 16: 0) \ldots$ \\
\hline 2192.67 & 241 & GT1 $(\mathrm{d} 18: 1 / 24: 0)$ or $(\mathrm{d} 20: 1 / 22: 0)$ or $(\mathrm{d} 22: 1 / 20: 0)$ or $(\mathrm{d} 24: 1 / 18: 0) \ldots-\mathrm{H}_{2} \mathrm{O}$ \\
\hline 2197.21 & 50 & OAc GT1 $(\mathrm{d} 18: 1 / 20: 0)$ or $(\mathrm{d} 20: 1 / 18: 0)$ or $(\mathrm{d} 22: 1 / 16: 0)$ or $(\mathrm{d} 24: 1 / 14: 0) \ldots$ \\
\hline 2209.08 & 27 & GT1 $(\mathrm{d} 18: 1 / 24: 1)$ or $(\mathrm{d} 20: 1 / 22: 1)$ or $(\mathrm{d} 22: 1 / 20: 1)$ or $(\mathrm{d} 24: 1 / 18: 1) \ldots$ \\
\hline 2218.97 & 86 & GT1 $(\mathrm{d} 18: 1 / 26: 1)$ or $(\mathrm{d} 20: 1 / 24: 1)$ or $(\mathrm{d} 22: 1 / 22: 1)$ or $(\mathrm{d} 24: 1 / 20: 1) \ldots-\mathrm{H}_{2} \mathrm{O}$ \\
\hline
\end{tabular}

a Only most likely ceramide residues are shown.

b Structures assigned manually; phospholipids are not included in the database.

in 13th g.w. fetal brain) could be due to difference in analyzed brain regions as well as due to small differences in developmental age of the analyzed fetal brains. ${ }^{11}$ Overall, the obtained data are consistent with previous studies and could argue the credibility and reliability of our new developed ganglioside database.

\subsubsection{Adult human brain ganglioside analysis}

A native ganglioside mixture isolated from adult human brain cortex (54 years) was analyzed in accordance with the data analysis principle previously explained, vide supra. The final search results are shown in Table 2 . The adult brain sample showed all common ganglioside species usually present in adult human brain $^{46}$ (highly abundant structurally complex gangliosides GM1, GD1, GT1, and less abundant simple gangliosides GM3, GM2, GD3, GD2), as well as O-acetylated GD1 and GT1 gangliosides and sulfatides, which were previously not detected in fetal human brain. The highest intensity signal corresponds to GD1 (d20:1/ 18:0) and second highest to GT1 (d20:1/18:0), which correlates with previously reported higher ratio of d20/d18-sphingoid bases in adult human brain, opposite from the ratio in fetal human brain. ${ }^{44}$ Altogether, 34 different ganglioside structures, 5 sulfatides, and 1 neutral GSL species were characterized in the analyzed mixture from adult human brain cortex, which is 19 structures more than previously identified (manually interpreted) in ganglioside mixture isolated from adult human hippocampus (20 years). ${ }^{25}$

\subsubsection{Calf brain ganglioside analysis}

Results of the analysis of ganglioside mixture isolated from calf brain are summarized in Table 3. The calf brain sample displayed all common ganglioside species characteristically present in adult human brain (GM1, GD1, GT1, GM3, GM2, GD3, and O-Ac-GD1). Moreover, an additional O-Ac-GD1 ganglioside containing one NeuGc-residue (instead of NeuAc-residue) was detected. As evidenced, NeuGc-containing glycans rarely occur in the brain of vertebrates, and are absent in human brain. ${ }^{47}$ Altogether, in the analyzed mixture from calf brain, 16 ganglioside structures, 1 sulfatide, and 3 neutral GSL species were identified. 
Table 3

Ganglioside composition of calf brain tissue, as obtained by matching experimental MS data with the GSL-finder MS and MSMS database search

\begin{tabular}{|c|c|c|}
\hline Experimental $(m / z)$ & Mass accuracy (ppm) & Proposed structure ${ }^{a}$ \\
\hline 806.65 & 111 & Phosphatidylserine $(38: 6)^{\mathrm{b}}$ \\
\hline 822.55 & 11 & $\mathrm{HSO}_{3}-\mathrm{Hex}-\mathrm{Cer}(\mathrm{t} 18: 1 / 18: 0)$ or $(\mathrm{t} 18: 0 / 18: 1)$ \\
\hline 857.68 & 187 & Phosphatidylinositol $(36: 4)^{\mathrm{b}}$ \\
\hline 862.70 & 86 & LacCer $(\mathrm{d} 18: 0 / 16: 0)$ or $(\mathrm{d} 20: 0 / 14: 0)$ or $(\mathrm{d} 16: 0 / 18: 0)$ \\
\hline 885.65 & 113 & Phosphatidylinositol $(18: 0 / 20: 4)=(38: 4)^{\mathrm{b}}$ \\
\hline 890.68 & 25 & LacCer $(\mathrm{d} 18: 0 / 18: 0)$ or $(\mathrm{d} 20: 0 / 16: 0)$ or $(\mathrm{d} 22: 0 / 14: 0)$ or $(\mathrm{d} 16: 0 / 20: 0)$ \\
\hline 906.69 & 42 & LacCer (t18:0/18:0) \\
\hline 1179.58 & 133 & GM3 (d18:1/18:0) or $(\mathrm{d} 20: 1 / 16: 0)$ or $(\mathrm{d} 22: 1 / 14: 0)$ or $(\mathrm{d} 18: 0 / 18: 1) \ldots$ \\
\hline 1382.80 & 12 & GM2 $(\mathrm{d} 18: 1 / 18: 0)$ or $(\mathrm{d} 20: 1 / 16: 0)$ or $(\mathrm{d} 22: 1 / 14: 0)$ or $(\mathrm{d} 18: 0 / 18: 1) \ldots$ \\
\hline 1410.93 & 58 & GM2 (d18:1/20:0) or $(\mathrm{d} 20: 1 / 18: 0)$ or $(\mathrm{d} 22: 1 / 16: 0)$ or $(\mathrm{d} 24: 1 / 14: 0) \ldots$ \\
\hline 1470.80 & 22 & GD3 $(\mathrm{d} 18: 1 / 18: 0)$ or $(\mathrm{d} 20: 1 / 16: 0)$ or $(\mathrm{d} 22: 1 / 14: 0)$ or $(\mathrm{d} 18: 0 / 18: 1) \ldots$ \\
\hline 1516.80 & 25 & GM1 $(\mathrm{d} 18: 1 / 16: 0)$ or $(\mathrm{d} 20: 1 / 14: 0)$ or $(\mathrm{d} 18: 0 / 16: 1)$ or $(\mathrm{d} 20: 0 / 14: 1) \ldots$ \\
\hline 1544.89 & 13 & GM1 (d18:1/18:0) or $(\mathrm{d} 20: 1 / 16: 0)$ or $(\mathrm{d} 22: 1 / 14: 0)$ or $(\mathrm{d} 18: 0 / 18: 1) \ldots$ \\
\hline 1572.91 & 6 & GM1 (d18:1/20:0) or $(\mathrm{d} 20: 1 / 18: 0)$ or $(\mathrm{d} 22: 1 / 16: 0)$ or $(\mathrm{d} 24: 1 / 14: 0) \ldots$ \\
\hline 1835.98 & 8 & GD1 $(\mathrm{d} 18: 1 / 18: 0)$ or $(\mathrm{d} 20: 1 / 16: 0)$ or $(\mathrm{d} 22: 1 / 14: 0)$ or $(\mathrm{d} 18: 0 / 18: 1) \ldots$ \\
\hline 1877.96 & 8 & OAc GD1 (d18:1/18:0) or $(\mathrm{d} 20: 1 / 16: 0)$ or $(\mathrm{d} 22: 1 / 14: 0)$ or $(\mathrm{d} 18: 0 / 18: 1) \ldots$ \\
\hline 1892.00 & 14 & GD1 $(\mathrm{d} 18: 1 / 22: 0)$ or $(\mathrm{d} 20: 1 / 20: 0)$ or $(\mathrm{d} 22: 1 / 18: 0)$ or $(\mathrm{d} 24: 1 / 16: 0) \ldots$ \\
\hline 1905.99 & 9 & OAc GD1 $(\mathrm{d} 18: 1 / 20: 0)$ or $(\mathrm{d} 20: 1 / 18: 0)$ or $(\mathrm{d} 22: 1 / 16: 0)$ or $(\mathrm{d} 24: 1 / 14: 0) \ldots$ \\
\hline 1921.94 & 32 & OAc GD1 (NeuAcNeuGc) (d18:1/20:0) or $(\mathrm{d} 20: 1 / 18: 0)$ or $(\mathrm{d} 22: 1 / 16: 0) \ldots$ \\
\hline 1931.78 & 125 & GD1 (t18:1/24:2) \\
\hline 2067.06 & 28 & (HexNAc) GD1 (d18:1/20:0) or $(\mathrm{d} 20: 1 / 18: 0)$ or $(\mathrm{d} 22: 1 / 16: 0) \ldots$ \\
\hline 2127.01 & 24 & GT1 $(\mathrm{d} 18: 1 / 18: 0)$ or $(\mathrm{d} 20: 1 / 16: 0)$ or $(\mathrm{d} 22: 1 / 14: 0)$ or $(\mathrm{d} 18: 0 / 18: 1) \ldots$ \\
\hline $2149.02^{\mathrm{Na}}$ & 13 & GT1 (d18:1/18:0) or $(\mathrm{d} 20: 1 / 16: 0) \ldots+\mathrm{Na}$ \\
\hline 2155.06 & 15 & GT1 $(\mathrm{d} 18: 1 / 20: 0)$ or $(\mathrm{d} 20: 1 / 18: 0)$ or $(\mathrm{d} 22: 1 / 16: 0)$ or $(\mathrm{d} 24: 1 / 14: 0) \ldots$ \\
\hline $2177.07^{\mathrm{Na}}$ & 11 & GT1 $(\mathrm{d} 18: 1 / 20: 0)$ or $(\mathrm{d} 20: 1 / 18: 0) \ldots+\mathrm{Na}$ \\
\hline
\end{tabular}

a Only most likely ceramide residues are shown.

b Structures assigned manually; phospholipids are not included in the database.

\section{Conclusions}

Presented computationally created database of GSL species ions and GSL-finder application provide a simple and automated routine for the GSL identification via MS and/or MSMS ion search. The database contains ganglioside and sulfo-GSL structures, as well as their neutral counterparts, with high diversity of ceramide compositions, sialic acid structures, and possible additional substitutions (modifications), including those proposed to occur in pathologically changed biomaterial (e.g., tumors).

The GSL-finder MSMS application takes full advantage of the fact that major product ions (Y-and Z-ions) of a GSL fragmentation pattern are structurally identical to the corresponding simpler GSL/ ceramide species, so accordingly simplifies a tandem MS ion search by using the MS ion database for matching tandem MS spectra. Validation results showed consistency with previous studies, vast improvement in speed over manual interpretation taking into account that the data can be quickly re-analyzed choosing different parameters.

In summary, newly developed database and application facilitate negative ion mass spectrometric analysis of complex glycosphingolipid mixtures isolated from various healthy and pathological biomaterials (tissues, cell cultures, body fluids, etc.).

\section{Nomenclature section}

The abbreviated designation of carbohydrates and glycosphingolipids follows the recommendations of IUPAC-IUB Commission on Biochemical Nomenclature ${ }^{48,49}$ and gangliosides are abbreviated according to the system of Svennerholm ${ }^{50,51}$ as follows: LacCer, Gal $\beta 4$ Glc $\beta 1$ Cer; GA2, Gg $_{3}$ Cer, GalNAc $\beta 4$ Gal $\beta 4$ Glc $\beta 1 C e r$; GA1, Gg ${ }_{4}$ Cer, Gal $\beta 3$ GalNAc $\beta 4$ Gal $\beta 4$ Glc $\beta 1$ Cer; Lc $c_{3}$, GlcNAc $\beta 3$ Gal $\beta$ 4 Glc $\beta 1$ Cer; $\mathrm{Lc}_{4}$, Gal $\beta 3 \mathrm{GlcNAc} \beta 3 \mathrm{Gal} \beta 4 \mathrm{Glc} \beta 1 \mathrm{Cer}$; nLc 4 , Gal $\beta 4 \mathrm{Glc}-$ NAc $\beta 3$ Gal $\beta 4 G l c \beta 1 C e r ; \quad n_{L} c_{6}, \quad$ Gal $\beta 4 G l c N A c \beta 3 G a l \beta 4 G l c N A c \beta 3 G a l \beta$ 4 Glc $\beta 1$ Cer; $\mathrm{Gb}_{3}$, Gal $\alpha 4$ Gal $\beta 4$ Glc $\beta 1 \mathrm{Cer} ; \mathrm{Gb}_{4}$, GalNAc $\beta 3$ Gal $\alpha 4$ Gal $\beta 4$ Glc $\beta 1$ Cer; iGb ${ }_{3}$, Gal $\alpha 3$ Gal $\beta 4$ Glc $\beta 1$ Cer; iGb 4 , GalNAc $\beta 3$ Gal $\alpha 3$ Gal $\beta$ 4Glc $\beta 1$ Cer; GM3, II ${ }^{3}-\alpha$-Neu5Ac-LacCer; GD3, II $^{3}-\alpha-(\text { Neu5Ac) })_{2}$-LacCer;
GT3, II ${ }^{3}-\alpha-(\mathrm{Neu} 5 \mathrm{Ac})_{3}$-LacCer; GM2, II ${ }^{3}-\alpha-\mathrm{Neu} 5 \mathrm{Ac}-\mathrm{Gg}_{3} \mathrm{Cer}$; GD2, $\mathrm{II}^{3}-\alpha-(\mathrm{Neu} 5 \mathrm{Ac})_{2}-\mathrm{Gg}_{3} \mathrm{Cer}$; GM1a or GM1, II ${ }^{3}-\alpha-\mathrm{Neu} 5 \mathrm{Ac}-\mathrm{Gg}_{4} \mathrm{Cer}$; GM1b, IV ${ }^{3}-\alpha-N e u 5 A c-G g_{4}$ Cer; GalNAc-GM1b, IV ${ }^{3}-\alpha-N e u 5 A c-G g_{5}$ Cer; GD1a, IV ${ }^{3}-\alpha-N e u 5 A c, I^{3}-\alpha-N e u 5 A c-G g_{4}$ Cer; GD1b, II ${ }^{3}-\alpha-$ $(\mathrm{Neu} 5 \mathrm{Ac})_{2}-\mathrm{Gg}_{4} \mathrm{Cer}$; GT1b, IV ${ }^{3}-\alpha-\mathrm{Neu} 5 \mathrm{Ac}, \mathrm{II}^{3}-\alpha-(\mathrm{Neu} 5 \mathrm{Ac})_{2}-\mathrm{Gg}_{4} \mathrm{Cer}$; GQ1b, IV ${ }^{3}-\alpha-($ Neu $\left.5 A c)\right)_{2}, I^{3}-\alpha-(\text { Neu } 5 A c)_{2}-G_{4}$ Cer.

\section{Acknowledgment}

The Ministry of Science, Education, and Sports of Republic of Croatia supported this work (Grant Numbers: 098-0982915-2945 and 108-1081870-2415).

\section{Supplementary data}

Supplementary data associated with this article can be found, in the online version, at http://dx.doi.org/10.1016/j.carres.2014. 06.029.

\section{References}

1. Yu, R. K.; Tsai, Y. T.; Ariga, T.; Yanagisawa, M. J. Oleo Sci. 2011, 60, 537-544.

2. Regina Todeschini, A.; Hakomori, S. Biochim. Biophys. Acta, Gen. Subj. 2008, 1780, 421-433.

3. Boggs, J. M.; Gao, W.; Zhao, J.; Park, H. J.; Liu, Y.; Basu, A. FEBS Lett. 2010, 584, $1771-1778$.

4. Boggs, J. M.; Gao, W.; Hirahara, Y. Biochim. Biophys. Acta, Gen. Subj. 2008, 1780, 445-455.

5. Kasahara, K.; Sanai, Y. Glycoconjugate J. 2000, 17, 153-162.

6. Yu, R. K.; Nakatani, Y.; Yanagisawa, M. J. Lipid Res. 2009, 50, S440-S445.

7. Kračun, I.; Rösner, H.; Drnovšek, V.; Vukelić, Ž.; Ćosović, Č.; Trbojević-Čepe, M.; Kubat, M. Neurochem. Int. 1992, 20, 421-431.

8. Jungalwala, F. B. Neurochem. Res. 1994, 19, 945-957.

9. Yu, R. K.; Yoshino, H.; Yamawaki, M.; Yoshino, J. E.; Ariga, T. J. Biomed. Sci. 1994, $1,167-171$.

10. Ogawa-Goto, K.; Ohta, Y.; Kubota, K.; Funamoto, N.; Abe, T.; Taki, T.; Nagashima, K. J. Neurochem. 1993, 61, 1398-1403.

11. Vukelić, Ž.; Metelmann, W.; Müthing, J.; Kos, M.; Peter-Katalinić, J. Biol. Chem. 2001, 382, 259-274.

12. Hakomori, S. Proc. Natl. Acad. Sci. U.S.A. 2002, 99, 10231-10233.

13. Ariga, T.; Suetake, K.; Nakane, M.; Kubota, M.; Usuki, S.; Kawashima, I.; Yu, R. K. NeuroSignals 2008, 16, 226-234. 
14. Shida, K.; Misonou, Y.; Korekane, H.; Seki, Y.; Noura, S.; Ohue, M.; Honke, K.; Miyamoto, Y. Glycobiology 2009, 19, 1018-1033.

15. Vukelić, Ž.; Kalanj-Bognar, S.; Froesch, M.; Bîndilâ, L.; Radić, B.; Allen, M.; PeterKatalinić, J.; Zamfir, A. D. Glycobiology 2007, 17, 504-515.

16. Liu, Y.; Chen, Y.; Momin, A.; Shaner, R.; Wang, E.; Bowen, N. J.; Matyunina, L. V.; Walker, L. D.; McDonald, J. F.; Sullards, M. C.; Merrill, A. H., Jr. Mol. Cancer 2010. http://dx.doi.org/10.1186/1476-4598-9-186.

17. Zamfir, A.; Serb, A.; Vukelić, Ž.; Flangea, C.; Schiopu, C.; Fabris, D.; KalanjBognar, S.; Capitan, F.; Sisu, E. J. Am. Soc. Mass Spectrom. 2011, 22, 2145-2159.

18. Lopez, P. H.; Schnaar, R. L. Curr. Opin. Struct. Biol. 2009, 19, 549-557.

19. Metelmann, W.; Vukelić, Ž.; Peter-Katalinić, J. J. Mass Spectrom. 2001, 36, 2129.

20. Zamfir, A.; Vukelić, Ž.; Bindila, L.; Peter-Katalinić, J.; Almeida, R.; Sterling, A.; Allen, M. J. Am. Soc. Mass Spectrom. 2004, 15, 1649-1657.

21. Dreisewerd, K.; Muthing, J.; Rohlfing, A.; Meisen, I.; Vukelić, Ž.; Peter-Katalinić, J.; Hillenkamp, F.; Berkenkamp, S. Anal. Chem. 2005, 77, 4098-4107.

22. Müthing, J.; Distler, U. Mass Spectrom. Rev. 2010, 29, 425-479.

23. Köfeler, H.; Fauland, A.; Rechberger, G.; Trötzmüller, M. Metabolites 2012, 2, 19-38.

24. Vukelić, Ž.; Zamfir, A. D.; Bindila, L.; Froesch, M.; Peter-Katalinić, J.; Usuki, S.; Yu, R. K. J. Am. Soc. Mass Spectrom. 2005, 16, 571-580.

25. Vukelić, Ž.; Zarei, M.; Peter-Katalinić, J.; Zamfir, A. D. J. Chromatogr., A 2006, $1130,238-245$.

26. Zamfir, A.; Fabris, D.; Capitan, F.; Munteanu, C.; Vukelić, Ž.; Flangea, C. Anal. Bioanal. Chem. 2013, 405, 7321-7335.

27. Flangea, C.; Fabris, D.; Vukelić, Ž.; Zamfir, A. D. Aust. J. Chem. 2013, 66, 781-790.

28. Schiopu, C.; Vukelić, Ž.; Capitan, F.; Kalanj-Bognar, S.; Sisu, E.; Zamfir, A. D. Electrophoresis 2012, 33, 1778-1786.

29. Schiopu, C.; Flangea, C.; Capitan, F.; Serb, A.; Vukelic, Z.; Kalanj-Bognar, S.; Sisu, E.; Przybylski, M.; Zamfir, A. D. Anal. Bioanal. Chem. 2009, 395, 2465-2477.

30. Wenk, M. R. Cell 2010, 143, 888-895.

31. Yang, K.; Cheng, H.; Gross, R. W.; Han, X. Anal. Chem. 2009, 81, 4356-4368.

32. Herzog, R.; Schuhmann, K.; Schwudke, D.; Sampaio, J. L.; Bornstein, S. R.; Schroeder, M.; Shevchenko, A. PLoS One 2012, 7. http://dx.doi.org/10.1371/ journal.pone.0029851.
33. Fahy, E.; Sud, M.; Cotter, D.; Subramaniam, S. Nucleic Acid Res. 2007, 35, W606W612.

34. Souady, J.; Dadimov, D.; Kirsch, S.; Bindila, L.; Peter-Katalinić, J.; Vakhrushev, S. Y. Rapid Commun. Mass Spectrom. 2010, 24, 1039-1048.

35. Popa, I.; Pons, A.; Mariller, C.; Tai, T.; Zanetta, J. P.; Thomas, L.; Portoukalian, J. Glycobiology 2007, 17, 367-373.

36. Kohla, G.; Stockfleth, E.; Schauer, R. Neurochem. Res. 2002, 27, 583-592.

37. Svennerholm, L.; Fredman, P. Biochim. Biophys. Acta 1980, 617, 97-109.

38. Miyagi, T.; Takahashi, K.; Hata, K.; Shiozaki, K.; Yamaguchi, K. Glycoconjugate J. 2012, 29, 567-577.

39. Domon, B.; Costello, C. E. Glycoconjugate J. 1988, 5, 397-409.

40. Hsu, F. F.; Turk, J. J. Am. Soc. Mass Spectrom. 2004, 15, 536-546.

41. Sullards, M. C.; Allegood, J. C.; Kelly, S.; Wang, E.; Haynes, C. A.; Park, H.; Chen, Y.; Merrill, J. Methods Enzymol. 2007, 432, 83-115.

42. Mlinac, K.; Fabris, D.; Vukelić, Ž.; Rožman, M.; Heffer, M.; Kalanj Bognar, S. Carbohydr. Res. 2013, 382, 1-8.

43. Sullards, M. C.; Liu, Y.; Chen, Y.; Merrill, J. Biochim. Biophys. Acta, Mol. Cell Biol. Lipids 2011, 1811, 838-853.

44. Sonnino, S.; Chigorno, V. Biochim. Biophys. Acta, Rev. Biomembr. 2000, 1469, 63 77.

45. O'Brien, J. S.; Rouser, G. J. Lipid Res. 1964, 5, 339-342.

46. Svennerholm, L.; Boström, K.; Jungbjer, B.; Olsson, L. J. Neurochem. 1994, 63, $1802-1811$.

47. Davies, L.; Varki, A. Top. Curr. Chem. 2013. http://dx.doi.org/10.1007/ 128_2013_419.

48. Hoffmann-Ostenhof, O.; Cohn, W. E.; Braunstein, A. E. Eur. J. Biochem. 1977, 79, $11-21$.

49. Chester, M. A. Glycoconjugate J. 1999, 16, 1-6.

50. Svennerholm, L. J. Neurochem. 1963, 10, 613-623.

51. Svennerholm, L. Adv. Exp. Med. Biol. 1980, 125, 11. 